\title{
A Review of Most Relevant Complications of Transcatheter Aortic Valve Implantation
}

\author{
Siyamek Neragi-Miandoab and Robert E. Michler \\ Department of Cardiovascular and Thoracic Surgery, Montefiore Medical Center, Albert Einstein College of Medicine, \\ 3400 Bainbridge Avenue, MAP 5, New York, NY 10467, USA \\ Correspondence should be addressed to Siyamek Neragi-Miandoab; siyamekneragi@yahoo.com
}

Received 27 March 2013; Accepted 15 April 2013

Academic Editors: W. S. Aronow, T. Bharucha, W. Bloch, S. Chia, Y. Furukawa, and Y. Hayabuchi

Copyright (C) 2013 S. Neragi-Miandoab and R. E. Michler. This is an open access article distributed under the Creative Commons Attribution License, which permits unrestricted use, distribution, and reproduction in any medium, provided the original work is properly cited.

\begin{abstract}
Transcatheter aortic valve implantation (TAVI) has emerged for treating aortic stenosis in patients who are poor candidates for surgical aortic valve replacement. Currently, the balloon-expandable Edwards Sapien valve-which is usually implanted via a transfemoral or transapical approach - and the self-expanding CoreValve ReValving system-which is designed for retrograde application-are the most widely implanted valves worldwide. Although a promising approach for high-risk patients, the indication may be expanded to intermediate- and eventually low-risk patients in the future; however, doing so will require a better understanding of potential complications, risk factors for these complications, and strategies to individualize each patient to a different access route and a specific valve. This paper reviews the most relevant complications that may occur in patients who undergo catheter-based aortic valve implantation.
\end{abstract}

\section{Introduction}

Although surgical aortic valve replacement (SAVR) carries low morbidity and mortality rates, some patients are not surgical candidates and/or carry a high risk [1-3]. With the advent of transcatheter aortic valve implantation (TAVI), many high-risk patients have become eligible for AVR [4]. The early results of landmark studies demonstrated that TAVI improves hemodynamics and is an alternative to SAVR in high-risk patients [5-8]. Many patient characteristics (as seen in most cited series) are presented in Tables 1,2 , and $3[5,9-$ 19].

Coronary artery disease mandates revascularization at the time of AVR. The indication for TAVI has expanded to patients who have had previous cardiac surgery [20,21]. PCI before TAVI can be performed as staged or simultaneously with no increased mortality [22,23]. In a series of 125 patients who underwent TAVI with CoreValve (PCI + TAVI; $n=55$ versus TAVI only; $n=70$ ), the 30 -day mortality was $6 \%$ for patients who had TAVI only versus $2 \%$ for patients treated with PCI + TAVI [22].
Risk-scoring systems have been utilized to create some algorithms to select very-high-risk patients who would be appropriate candidates for TAVI. The logistic EuroSCORE (LES) and the Society of Thoracic Surgeons Predicted Risk of Mortality (STS-PROM) are the standard scoring systems. Some other risks include liver disease, frailty, porcelain aorta, and previous radiation; these have not yet been properly addressed in current scoring systems [24]. Considering the recent developments in this field, a new scoring system may be necessary to identify the best candidates for TAVI with a potential to expand the indication to intermediaterisk patients and possibly lower risk patients. Preoperative morbidities of patients who underwent TAVI using Edwards SAPIEN and CoreValve in the most relevant series in the current literature are shown in Tables 4 and 5 [5, 9-19].

\section{Most Widely Used Valves}

The two most widely used valves for TAVI are the Edwards Sapien valve (Edwards Lifesciences, Irvine, CA, USA) and 
TABLE 1: Preoperative patient characteristics.

\begin{tabular}{|c|c|c|c|c|c|c|c|}
\hline Series & Type of valve & Route & $N$ & Mean age & NYHA 3/4 & NYHA 4 & $\mathrm{EF} \%$ \\
\hline Makkar et al. [42] & Sapien & & 179 & 83.1 & $165(92 \%)$ & & 53.9 \\
\hline Kodali et al. [14] & Sapien & $\begin{array}{c}244 \text { transfemoral } \\
104 \text { transapical }\end{array}$ & 348 & 83.6 & $328(94 \%)$ & & 52.5 \\
\hline Thomas et al. $[12,13]$ & Sapien & 463 transfemoral & 463 & 81.7 & $353(76 \%)$ & $68(15 \%)$ & \\
\hline Thomas et al. $[12,13]$ & Sapien & 575 transapical & 575 & 80.7 & $446(78 \%)$ & $78(14 \%)$ & \\
\hline Himbert et al. [10] & Sapien & 51 transfemoral & 51 & 82 & $49(96 \%)$ & $22(43 \%)$ & 52 \\
\hline Himbert et al. [10] & Sapien & 24 transapical & 24 & 82 & $22(92 \%)$ & $9(38 \%)$ & 48 \\
\hline Grube et al. [9] & CoreValve & & 136 & 81.6 & $130(96 \%)$ & & 51.5 \\
\hline Litzler et al. [15] & Sapien & & 61 & 81 & $44(72 \%)$ & & 56.3 \\
\hline Tamburino et al. [16] & CoreValve & $\begin{array}{l}599 \text { transfemoral } \\
64 \text { transsubclavian }\end{array}$ & 663 & 81 & $434(71.5 \%)$ & & 52.1 \\
\hline Avanzas et al. [17] & CoreValve & & 108 & 78.6 & $63(58.4 \%)$ & $22(20.4 \%)$ & \\
\hline Kempfert et al. [11] & Sapien & 299 transapical & 299 & 82 & $252(84 \%)$ & $53(18 \%)$ & 55.3 \\
\hline Gotzmann et al. [18] & CoreValve & & 145 & 79.1 & $138(95 \%)$ & $34(23 \%)$ & 55.8 \\
\hline Bleiziffer et al. [19] & Sapien and CoreValve & & 227 & 81 & $218(96 \%)$ & & \\
\hline
\end{tabular}

TABle 2: Patients' preoperative risk factors.

\begin{tabular}{|c|c|c|c|c|c|c|}
\hline Series & Type of Valve & h/o CVA & h/o PVD & Renal disease & STS score & EuroSCORE \\
\hline Makkar et al. [42] & Sapien & $48(27 \%)$ & $54(30 \%)$ & & 11.2 & 26.4 \\
\hline Kodali et al. [14] & Sapien & $95(27 \%)$ & $148(43 \%)$ & & 11.8 & 29.3 \\
\hline Thomas et al. $[12,13]$ & Sapien & & $49(11 \%)$ & $121(26 \%)$ & & 25.7 \\
\hline Thomas et al. $[12,13]$ & Sapien & & $161(28 \%)$ & $189(33 \%)$ & & 29.1 \\
\hline Himbert et al. [10] (TF) & Sapien & & $4(8 \%)$ & $16(31 \%)$ & 15 & 25 \\
\hline Himbert et al. [10] (TA) & Sapien & & $7(30 \%)$ & $12(52 \%)$ & 18 & 28 \\
\hline Grube et al. [9] & CoreValve & $11(8 \%)$ & $28(21 \%)$ & $38(28 \%)$ & 8.9 & 23.4 \\
\hline Litzler et al. [15] & Sapien & $6(10 \%)$ & & & & 27.5 \\
\hline Tamburino et al. [43] & CoreValve & $48(7 \%)$ & $127(19 \%)$ & $154(23 \%)$ & & 23 \\
\hline Avanzas et al. [17] & CoreValve & & & & & 16 \\
\hline Kempfert et al. [11] & Sapien & & $142(48 \%)$ & $8(3 \%)$ & 12 & 31 \\
\hline Gotzmann et al. [18] & CoreValve & & & & & 21 \\
\hline Bleiziffer et al. [19] & Sapien and CoreValve & $26(11 \%)$ & $61(27 \%)$ & $48(21 \%)$ & 7 & 21 \\
\hline
\end{tabular}

TABle 3: Previous cardiac conditions.

\begin{tabular}{|c|c|c|c|c|c|c|}
\hline Series & Type of valve & COPD & $\mathrm{CAD}$ & h/o MI & $\mathrm{h} / \mathrm{o} \mathrm{CABG}$ & h/o PCI \\
\hline Makkar et al. [42] & Sapien & $74(41 \%)$ & $121(68 \%)$ & $33(18 \%)$ & $58(32 \%)$ & $47(26 \%)$ \\
\hline Kodali et al. [14] & Sapien & $151(43 \%)$ & $260(75 \%)$ & $92(26 \%)$ & $147(42 \%)$ & $116(33 \%)$ \\
\hline Thomas et al. $[12,13]$ & Sapien & & $220(48 \%)$ & $10(2 \%)$ & $81(17 \%)$ & \\
\hline Thomas et al. $[12,13]$ & Sapien & & $317(55 \%)$ & $10(2 \%)$ & $155(27 \%)$ & \\
\hline Himbert et al. [10] (TF) & Sapien & $14(27 \%)$ & $25(49 \%)$ & $4(8 \%)$ & $11(22 \%)$ & $7(20 \%)$ \\
\hline Himbert et al. [10] (TA) & Sapien & $6(26 \%)$ & $20(87 \%)$ & $11(48 \%)$ & $12(52 \%)$ & $4(27 \%)$ \\
\hline Grube et al. [9] & CoreValve & & $81(60 \%)$ & $35(26 \%)$ & $41(30 \%)$ & \\
\hline Litzler et al. [15] & Sapien & & & $22(36 \%)$ & $21(34 \%)$ & $23(38 \%)$ \\
\hline Tamburino et al. [16] & CoreValve & $141(21 \%)$ & $320(48 \%)$ & $143(22 \%)$ & $104(16 \%)$ & $189(29 \%)$ \\
\hline Avanzas et al. [17] & CoreValve & & $36(33 \%)$ & & $9(8 \%)$ & $15(14 \%)$ \\
\hline Kempfert et al. [11] & Sapien & $129(43 \%)$ & $159(53 \%)$ & $8(3 \%)$ & & \\
\hline Gotzmann et al. [18] & CoreValve & & & & & \\
\hline Bleiziffer et al. [19] & Sapien and CoreValve & $52(23 \%)$ & $118(52 \%)$ & & & \\
\hline
\end{tabular}


the CoreValve (ReValving Technology Medtronic Inc., Minneapolis, MN, USA) $[4,25,26]$. The Sapien valve can be used for antegrade (transapical) or for retrograde (transfemoral, transsubclavian, or transaortic) approaches. It has been implanted in the pulmonary artery or inside a degenerative biologic prosthesis in aortic as well as in mitral position recently $[4,27,28]$. Many devices with a self-expanding frame have been introduced into clinical practice $[4,29,30]$. Of these, the CoreValve for retrograde implantation has been the most widely used [31]. The CoreValve is a self-expanding device whereas the Edwards Sapien valve requires a balloon to expand it [32]. Early experience with larger delivery sheaths $(>18 \mathrm{Fr}$ ) demonstrated a relatively high incidence of vascular complications with a negative impact on survival. The new generation of delivery devices has smaller diameter in order to reduce vascular complications. The CoreValve products have a broad range of valve sizes to fit to annular diameters of $18 \mathrm{~mm}$ to $31 \mathrm{~mm}$ and can be implanted via an 18 Fr catheter $[33,34]$.

\section{Delivery Route}

One of the unique aspects for successful TAVI involves the ability to secure an access route for deployment of the aortic valve. TAVI can be performed through many access routes including retrograde transfemoral, retrograde transsubclavian, retrograde transaortic, and antegrade transapical [11, 26, $35,36]$. The transfemoral approach has been the most widely used and is commonly the first choice for access. Because of the large delivery system, it is crucial to carefully evaluate the iliofemoral vessels as well as the amount of atherosclerosis and plaque in the aortic arch and ascending aorta [37]. In cases of severe calcifications of femoral and iliac arteries as well as the aorta (Figure 1), the transapical (TA-) AVI is a viable alternative [38]. The TA-AVI reduces the vascular complications; further, shorter catheter length and using the antegrade approach may allow for more precise control of the device [39]. A transsubclavian approach for TAVI is a reasonable option in patients with peripheral vasculopathy [40, 41]. Petronio et al. [41] compared the outcome of TAVI with the subclavian approach $(n=141)$ with a propensity matched group of 141 patients who had undergone TAVI with the transfemoral approach. The two groups showed similar procedural success; however, incidence of acute kidney injury (AKI) stage III, vascular complications, and bleeding was lower with the subclavian approach. The midterm survival rate and freedom from cardiovascular death were similar in both groups.

\section{Complications}

The recently introduced Valve Academic Research Consortium (VARC) 1 [44] and 2 [45] criteria may help to standardize documentation of postoperative complications like myocardial infarction, stroke, bleeding, acute kidney injury, vascular complications, and valve performance, as well as the risk of mortality [44, 45]. Malpositioning, valve migration/embolization, conversion to open surgery, renal failure,

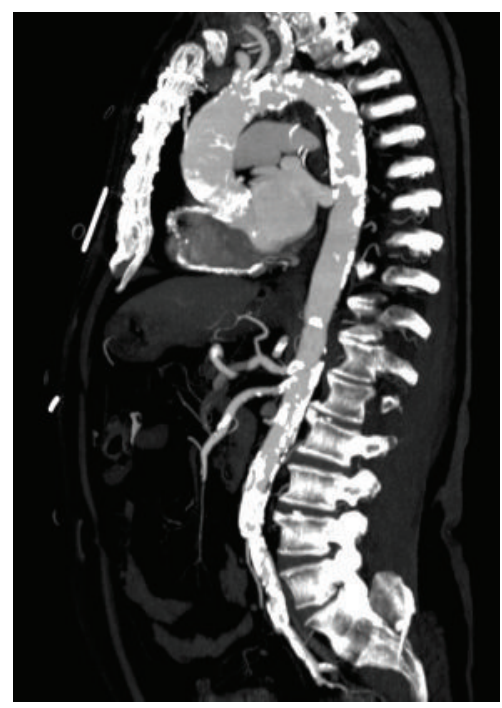

FIGURE 1: Severe calcifications of femoral and iliac vessels as well as aorta, aortic arch, and annulus, which carry a high risk of vascular complications, embolic stroke, and paravalvular leak. A transapical approach would be safer in this scenario.

need for pacemaker implantation, stroke, and myocardial infarct are other major complications following TAVI [27]. Blocking the coronary ostia, limiting the anterior mitral leaflet mobility, and atrioventricular conduction system are some frequently encountered perioperative complications $[39,46]$.

Prosthesis dislocation during TAVI is a rare but serious complication. It can be managed effectively by implanting a second device (Figure 2) and leaving the dislocated device safely in the aorta or complete retrieval of valve (Figure 3) [47]. In series of 181 patients (the Italian CoreValve Registry) it was shown that patients who experienced major or lifethreatening bleeding after procedure had a higher rate of mortality. Patients with renal insufficiency, defined by VARC 1 [44] and VARC 2 [45] criteria, had a higher mortality rate at 3-year followup (49\% versus 29\%) [48]. Patients with LES > 20 also have higher mortality (25.7\% versus $6.8 \%$ ) at 12 months compared with patients with LES $<20$ [43]. In addition to LES, renal disease, liver disease, low baseline LVEF, and smoking are risk factors for 1-year mortality $[12,49-51]$. Tables 5 and 6 demonstrate the postoperative outcomes and most frequent complications in some of the major series in the current literature.

4.1. Vascular Complications. The transfemoral approach is associated with higher vascular complications compared to the TA-TAVI (Figure 4), [5, 39, 50, 52-54] although the trend toward reduced sheath size has shown a significant reduction in vascular complications [55]. Proper patient selection by using appropriate preoperative imaging (vascular CT scan and angiography) may reduce vascular complications [55]. Considering the fragile condition of patients who undergo TAVI, a percutaneous arterial closure device (Prostar) has 
TABLE 4: Preoperative hemodynamic characteristics.

\begin{tabular}{|c|c|c|c|c|c|c|}
\hline Series & Type of valve & $\begin{array}{c}\text { Mean AV gradient } \\
(\mathrm{mm} \mathrm{Hg})\end{array}$ & $\begin{array}{c}\text { Aortic valve } \\
\text { area }\left(\mathrm{cm}^{2}\right)\end{array}$ & $\begin{array}{c}\text { Mitral regurgitation } \\
\text { (moderate-severe) }\end{array}$ & $\begin{array}{l}\text { Permanent } \\
\text { pacemaker }\end{array}$ & Pulm HTN \\
\hline Makkar et al. [42] & Sapien & 44.5 & 0.6 & $38(21 \%)$ & $35(20 \%)$ & $50(28 \%)$ \\
\hline Kodali et al. [14] & Sapien & 42.7 & 0.7 & $66(19 \%)$ & $69(20 \%)$ & $125(36 \%)$ \\
\hline Thomas et al. $[12,13]$ & Sapien & & & $73(16 \%)$ & & $114(25 \%)$ \\
\hline Thomas et al. $[12,13]$ & Sapien & & & $184(32 \%)$ & & $172(30 \%)$ \\
\hline Himbert et al. [10] (TF) & Sapien & 54 & 0.63 & & & \\
\hline Himbert et al. [10] (TA) & Sapien & 48 & 0.65 & & & \\
\hline Grube et al. [9] & CoreValve & 42 & 0.66 & & $14(10 \%)$ & $14(10 \%)$ \\
\hline Litzler et al. [15] & Sapien & 41 & 0.68 & & $11(18 \%)$ & \\
\hline Tamburino et al. [16] & CoreValve & 51.8 & & $42(6 \%)$ & $42(6 \%)$ & \\
\hline Avanzas et al. [17] & CoreValve & 55 & 0.63 & & & \\
\hline Kempfert et al. [11] & Sapien & & & $3(3 \%)$ & & $81(28 \%) 81$ \\
\hline Gotzmann et al.[18] & CoreValve & 46.6 & & $83(57 \%)$ & & $91(63 \%)$ \\
\hline Bleiziffer et al. [19] & Sapien and CoreValve & 48 & 0.6 & & & $53(23 \%)$ \\
\hline
\end{tabular}

TABLE 5: Postoperative outcome: cardiac and noncardiac related mortality.

\begin{tabular}{|c|c|c|c|c|c|c|}
\hline Series & Type of valve & Valve in valve & $\begin{array}{c}\text { Mortality } \\
30 \mathrm{~d}\end{array}$ & Mortality 1 yr & $\begin{array}{c}\text { Cardiac } \\
\text { mortality } 30 \mathrm{~d}\end{array}$ & $\begin{array}{c}\text { Cardiac } \\
\text { mortality } 1 \text { yr }\end{array}$ \\
\hline Makkar et al. [42] & Sapien & & $9(5 \%)$ & $55(31 \%)$ & $8(4 \%)$ & $35(20 \%)$ \\
\hline Kodali et al. [14] & Sapien & & $12(3 \%)$ & $84(24 \%)$ & $11(3 \%)$ & $47(14 \%)$ \\
\hline Thomas et al. $[12,13]$ & Sapien & $3(1 \%)$ & $29(6 \%)$ & $88(19 \%)$ & & $45(10 \%)$ \\
\hline Thomas et al. $[12,13]$ & Sapien & $19(3 \%)$ & $59(10 \%)$ & $156(27 \%)$ & & \\
\hline Himbert et al. [10] (TF) & Sapien & $1(2 \%)$ & $4(8 \%)$ & $6(12 \%)$ & $3(6 \%)$ & $2(4 \%)$ \\
\hline Himbert et al. [10] (TA) & Sapien & $2(8 \%)$ & $4(16 \%)$ & $8(32 \%)$ & $2(8 \%)$ & 0 \\
\hline Grube et al. [9] & CoreValve & $3(2 \%)$ & $17(13 \%)$ & $25(18 \%)$ & & \\
\hline Litzler et al. [15] & Sapien & & $8(13 \%)$ & $16(26 \%)$ & & \\
\hline Tamburino et al. [16] & CoreValve & $24(4 \%)$ & $39(6 \%)$ & $99(15 \%)$ & & \\
\hline Avanzas et al. [17] & CoreValve & $1(1 \%)$ & $8(7 \%)$ & $15(14 \%)$ & $6(6 \%)$ & \\
\hline Kempfert et al. [11] & Sapien & $17(6 \%)$ & $26(9 \%)$ & $78(26 \%)$ & & \\
\hline Gotzmann et al. [18] & CoreValve & & $12(8 \%)$ & & & \\
\hline Bleiziffer et al. [19] & Sapien and CoreValve & & $26(11 \%)$ & $70(25 \%)$ & $4(1.7 \%)$ & \\
\hline
\end{tabular}

been used to limit burden of the procedure; $[55,56]$ however, this approach has been reported to be associated with increased vascular complications [52]. In a series of transfemoral-TAVI, the percutaneous approach using Prostar was performed in 142 patients who underwent TAVI with Sapien valve $(n=109$, sheath size $18-24 \mathrm{~F})$ or CoreValve ( $n=31$, sheath size $18 \mathrm{~F})$; vascular complications occurred in $20 \%$ of participants, $3.6 \%$ of whom required surgical repair. A transfemoral approach with Sapien valve carries a higher risk for Prostar failure and vascular complications [52]. Other risk factors for life-threatening bleedings following TAVI include female gender, using a larger size delivery system (>19 Fr), peripheral arterial disease (PVD), valve retrieval (Figure 3), and percutaneous access [56]. The size of the delivery system has been reduced in recent years from previously 24 French to the actual 18-19 F [55]. Even smaller introducers have been announced by manufacturers and are anticipated to be available in near future.

Vascular complications after TAVI can be treated percutaneously with high technical success and acceptable clinical outcomes (Figure 4). In a series of 149 TAVI patients, the transfemoral percutaneous approach was associated with vascular complications in 27 patients (18\%). After a median followup of 10.9 months, imaging studies showed no evidence of hemodynamically significant stenosis in repaired femoral vessels [57]. Bleeding after TAVI is mostly related to vascular complications $[53,58]$. Blood transfusion following TAVI is associated with increased mortality at 1 year and increased risk of major stroke and acute kidney injury [59]. Reduced bleeding and less need for blood transfusion may improve outcomes in TAVI patients. Specific scores are needed to identify the patients who are at higher risk for 


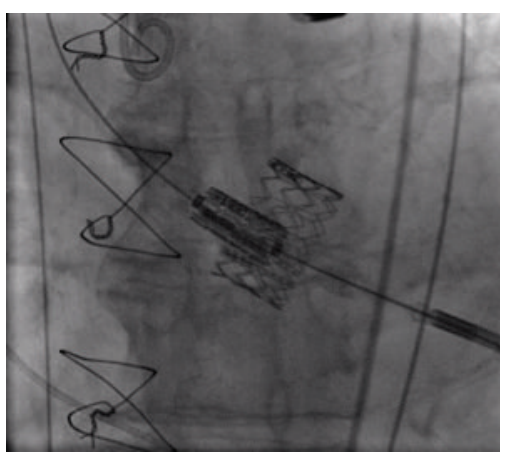

(a)

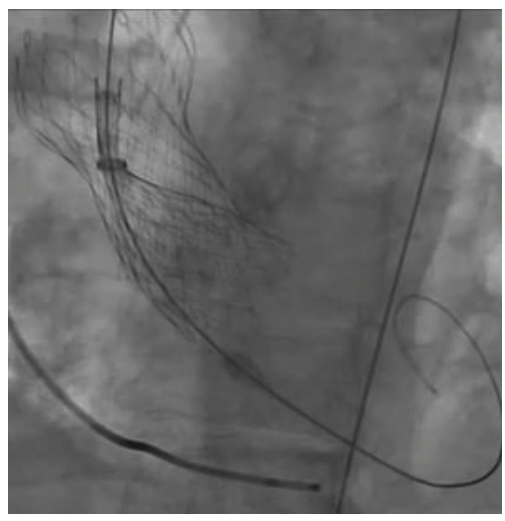

(c)

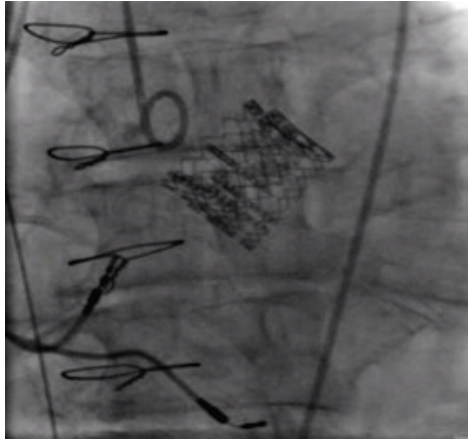

(b)

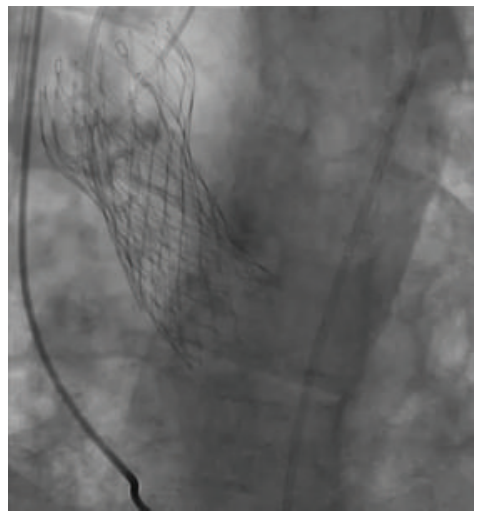

(d)

Figure 2: Valve-in-valve bailout procedure. (a) and (b) showing the valve-in-valve for Sapien valve and (c) and (d) for CoreValve.

TABLE 6: Postoperative cardiac-related complications.

\begin{tabular}{|c|c|c|c|c|c|}
\hline Series & Type of valve & CVA $30 \mathrm{~d}$ & CVA $1 \mathrm{yr}$ & 30 days, new pacemaker & $1 \mathrm{yr}$, new pacemaker \\
\hline Makkar et al. [42] & Sapien & $12(7 \%)$ & $19(11 \%)$ & $6(3 \%)$ & $8(4 \%)$ \\
\hline Kodali et al. [14] & Sapien & $19(5 \%)$ & $27(8 \%)$ & $13(4 \%)$ & $19(5 \%)$ \\
\hline Thomas et al. $[12,13]$ & Sapien & $11(2 \%)$ & $46(4 \%)$ & $31(7 \%)$ & \\
\hline Thomas et al. $[12,13]$ & Sapien & $16(3 \%)$ & & $42(7 \%)$ & \\
\hline Himbert et al. [10] (TF) & Sapien & $3(6 \%)$ & & $3(6 \%)$ & \\
\hline Grube et al. [9] & CoreValve & $6(4 \%)$ & $6(4 \%)$ & & \\
\hline Litzler et al. [15] & Sapien & & & & \\
\hline Tamburino et al. [16] & CoreValve & & $17(3 \%)$ & $110(17 \%)$ & $127(19 \%)$ \\
\hline Avanzas et al. [17] & CoreValve & & & & $38(35 \%)$ \\
\hline Kempfert et al. [11] & Sapien & $2(1 \%)$ & & $10(3 \%)$ & \\
\hline Gotzmann et al. [18] & CoreValve & & & & \\
\hline Bleiziffer et al. [19] & Sapien and CoreValve & $7(3 \%)$ & & & \\
\hline
\end{tabular}

TAVI-related vascular complications; this knowledge would enable providers to select a different access route in these patients when appropriate.

4.2. Stroke. Stroke remains a troublesome adverse event following TAVI. It is more frequent among patients who undergo TAVI than SAVR $[5,50,54,60]$ and is associated with reduced survival [61]. Cerebrovascular accidents occur mostly during the procedure or shortly thereafter and are more frequent with repeated attempts to implant the prosthesis [61]. TAVI causes a substantial amount of cerebral microemboli; importantly, the high number of the microemboli may correlate with the severity of the postprocedural cerebral injury $[62,63]$. In a series of 389 patients, Pilgrim [64] reported that age $>80$ years, body mass index $>20 \mathrm{~kg} / \mathrm{m}^{2}$, prior stroke, and atrial fibrillation (AF) may increase the risk of CVA in patients undergoing TAVI [64]. 

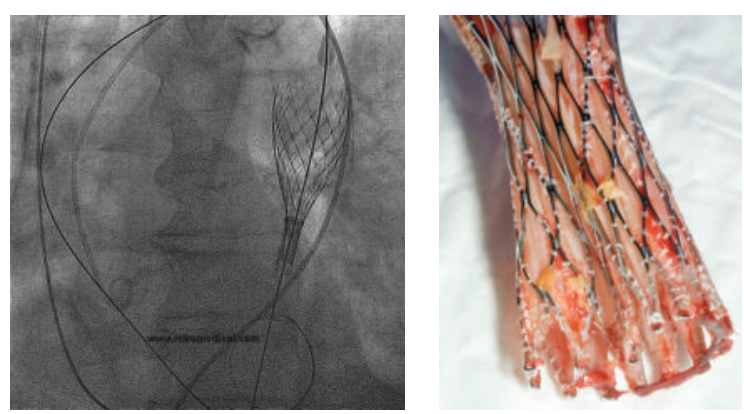

FIgURE 3: Valve retrieval. A retrieval of CoreValve is possible if the valve is not completely released; however, this maneuver carries a high risk for vascular complications and embolic stroke.

Stortecky et al. [61] reported a stroke incidence of 3.6\% in a series of 389 patients. Patients with CVA had an increased risk of all-cause ( $42.3 \%$ versus $5.1 \%$ ) and cardiovascular mortality (38.4\% versus $4.6 \%$ ) compared to patients without CVA at 30 day followup [61]. In a series of 214 patients who underwent TAVI using the CoreValve, stroke occurred in 19 patients (9\%) in the perioperative period. New-onset AF and baseline aortic regurgitation grade III or greater increased the risk of stroke [65]. In a larger series of 1,061 patients, cerebrovascular events (CVE) occurred in 54 patients (5\%) within 30 days of TAVI. The predictors of CVE in the acute/subacute period were postdilation of the prosthesis, valve embolization, and new-onset AF. Late CVEs occurred in 35 patients (3.3\%) at a median followup of $12(3-23)$ months. The predictors of late CVEs were chronic AF, PVD, and prior cerebrovascular disease (CVD). In a meta-analysis including 53 studies with a total of 10,037 patients who had undergone transfemoral, transapical, or transsubclavian TAVI, Eggebrecht et al. [40] reported that TAVI was associated with an average 30-day CVA of 3.3\%. The incidence of stroke was associated with access route; the lowest stroke rate was observed with the transapical approach (2.7\%). A major stroke following TAVI is associated with increased mortality within the first 30 days $[40,61,66]$.

Evaluation of cerebral microembolism following TAVI with magnetic resonance imaging (MRI) has demonstrated new foci of reduced diffusion. Reinsfelt et al. [63] reported that $37 \%$ of the instances of microembolism occurred during manipulation of the aortic arch/root/valve by guide wires and catheters, $22 \%$ occurred after balloon dilatation of the valve, and $41 \%$ occurred during implantation of the prosthesis. However, despite the evidence of microemboli, none of the patients developed neurological symptoms [63]. Multiple studies have shown no correlation between MRI-detected embolic events and a clinical CVA $[60,67,68]$. Recently, diffusion-weighted MRI (DW-MRI) studies have confirmed the phenomenon of new perfusion deficits and microemboli after TAVI [67, 69]. Following TAVI, many patients have demonstrated a higher rate of cognitive decline compared to SAVR; however, the brain lesions per patient and cumulative embolic load per patient in DW-MRI were not associated with postoperative cerebral microischemia, cognitive dysfunction [60], or increased mortality [67]. In a series of 39 patients [67], the DW-MRI following TAVI showed new embolic events in $72.0 \%$; however, only $6.6 \%$ of those patients had any clinically significant neurological deficits [67]. These "silent" cerebral infarctions occur frequently after TAVI yet have no clinical relevance $[67,68]$. In another series of 31 TAVI patients evaluated with MRI, multiple small (silent) cerebral infarcts occurred in $77 \%$ of patients. Patients who had multiple large embolic events were shown to have suffered a clinical stroke. Advanced age and severity of calcifications on the valve and aortic arch may increase the risk of embolic events following TAVI [68].

A protection device that can be placed on the aortic arch (inserted through radial $(7 \mathrm{~F})$ or contralateral femoral artery (9F)) may reduce the incidence of embolic events during TAVI [62]. The vast majority of embolic events and strokes are caused by embolization of atherosclerotic material and other debris from the stenotic valve during various phases of TAVI. Recently, Onsea et al. [70] reported their experience with a protection device (SMT Embolic Deflection Device) in 15 TAVI patients. A brain diffusion weighted (DW)-MRI detected 3.2 new cerebral lesions per patient who had an SMT filter placed compared to 7.2 new lesions per patient in the group without an SMT filter. None of their patients, both with and without SMT filter, developed new onset permanent neurological deficits or clinical findings of stroke; only 1 patient suffered a transient ischemic attack (TIA) [70]. Naber et al. [62] reported on the safety of the Claret CE Procerebral protection device (Claret Medical, Inc., Santa Rosa, CA, USA) in 35 patients undergoing TAVI. Evidence of captured debris was documented in at least 19 of 35 implanted devices (54.3\%). No periprocedural TIA, minor strokes, or major strokes were reported. Thirty-day followup showed that one minor stroke had occurred early in the 30 days after the procedure, and two major strokes occurred later in the 30 days after the procedure [62]. Considering the high cost of the cerebral protection devices, the expertise required to implant it, and the lack of documented benefits of using it, selecting the device should be individualized to each patient's condition, amount of calcification on the valve, and a history of previous cerebrovascular disease.

4.3. Renal Failure. TAVI has been shown to increase the risk of AKI (acute kidney injury) defined by the VARC 1 [44] and 2 [45] criteria. The incidence of AKI following TAVI ranges from $12 \%$ to $21 \%$ in different series and is associated with increased 30-day and 1-year mortality [13, 71-73]. Although in the majority of the cases AKI is reversible, AKI stage III may worsen the 1-year survival [72]. The predictors of AKI in TAVI patients include a history of diabetes mellitus, PVD, and advanced renal insufficiency [71]. In a prospective study of 150 TAVI patients (using CoreValve), Nuis et al. [49] reported a 30-day AKI of 19\%. Some authors reported a higher incidence of AKI following transapical TAVI [72]. Blood transfusion increased the risk of AKI following TAVI, which indicated that the outcome of TAVI may be improved by more restrictive use of blood transfusions [73, 74]. In a multicenter study evaluating 995 TAVI patients (CoreValve and Sapien valve), AKI occurred in 20.7\% $(n=206)$ [73]. 

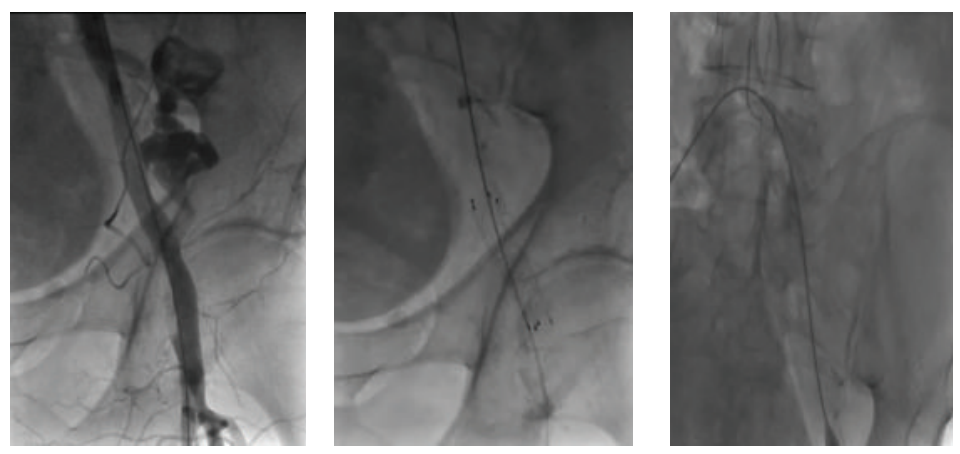

FIgURE 4: Perforation of left femoral artery and stent placement. A stent placement is easier and faster in presence of a crossover wire in the femoral artery.

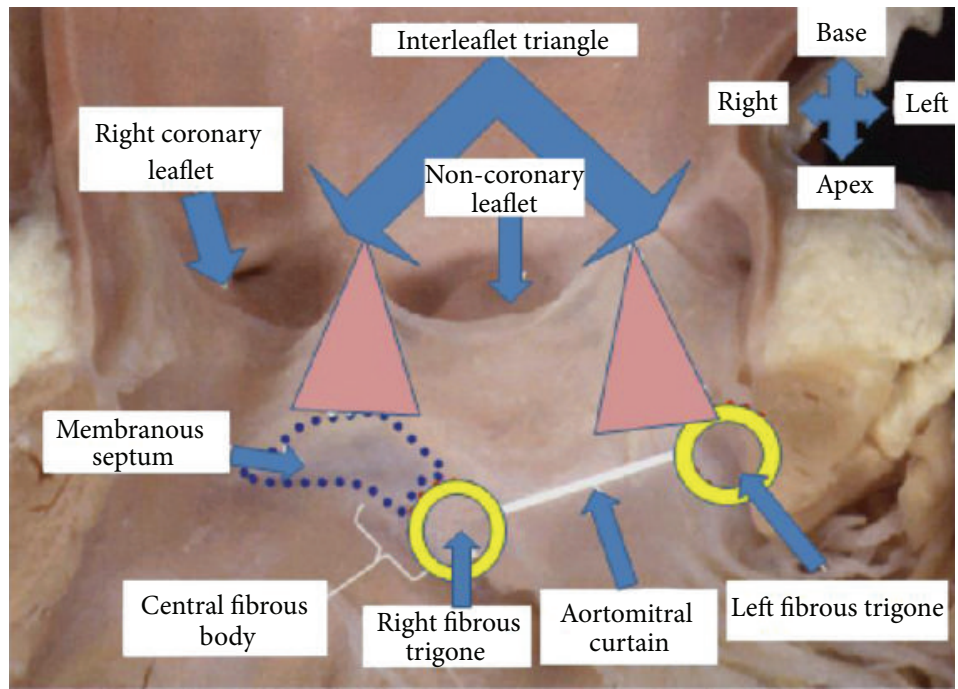

FIGURE 5: The anatomy of aortic valve, aortic root, coronary arteries orifice, and the conduction system. The proximity of coronary orifice and conduction system to the annulus may explain some of the complications of TAVI.

The number of units of blood transfusion was the strongest predictor of AKI; the second and third strongest predictors were PVD and a history of heart failure, respectively. AKI and life-threatening bleeding were independent predictors of 30-day mortality whereas transfusion, baseline anemia, and AKI predicted mortality beyond 30 days [73]. In their series of 102 patients of whom $87.3 \%$ had chronic kidney disease, Saia et al. [72] reported that a periprocedural AKI developed in 42 patients: $66.7 \%$ in the transapical group, $30.3 \%$ in the transfemoral group, and $50.0 \%$ in the transsubclavian group. The transapical approach was a significant predictor of AKI, but the strongest predictor of 1-year mortality was the postprocedural AKI III grade [72]. Other authors reported the transapical approach to be a risk factor for AKI [64, 74]. However, these statements might be biased because all patients who undergo the transapical approach have an advanced PVD that precludes the transfemoral approach. Thus, this association may only reaffirm the general condition of patients and the calcifications of certain arteries including renal arteries. The PVD and the number of units for blood transfusion have been reported to be risk factors for AKI after
TAVI [71, 73]. Further, a transapical approach may require more blood transfusion due to the nature of the procedure.

TAVI does not seem to increase the risk of morbidity and mortality in patients with end-stage renal disease (ESRD); therefore, it should be considered as an alternative to open surgery in dialysis patients [75]. Wessely et al. [75] evaluated the outcome of TAVI in patients with ESRD; all dialysis patients survived [75]. However, the patients with ESRD should be differentiated from patients with renal insufficiency, who still depend on their remaining kidney function; moreover, an AKI in the setting of a chronic kidney disease needs meticulous management.

4.4. Paravalvular Leak. The irregular surfaces of a native, calcified aortic valve may prevent a sealing between the prosthesis and the annulus, thereby increasing the risk of paravalvular leak following TAVI. During TAVI, the native valve is crushed against the aortic wall and into the sinuses of valsalva. These debris and calcifications are eventually trapped between the annulus and the prosthesis. Thus, a slight 
prosthesis insufficiency is not uncommon (i.e., reported in about $70 \%$ of patients for all types of valves used for TAVI) [16]. Annular calcification and bicuspid aortic valve are significant risk factors for paravalvular leak following TAVI $[76,77]$. Thus, preoperative cardiac CT is needed to assess the degree of calcification, which may predict the patient's risk of paravalvular leak. An accurate measurement of the aortic annulus is also crucial for reducing the risk of prosthesis mismatch (Figure 5, anatomy of the aortic root) [78]. An underexpansion of the prosthesis stent frame is a major risk factor for paravalvular leak, which might be caused by calcifications of the annulus or of the cusps of the native valve, prosthesis malposition (implantation depth, that is, too deep or too shallow), and/or annulusprosthesis-size mismatch. Recently published studies report an incidence of moderate/severe paravalvular leak of $15 \%$ to $20 \%$ following TAVI $[5,16,79-82]$. Evaluation of the severity of a paravalvular leak following valve implantation is critical; it has been shown to correlate with short- and long-term outcomes $[16,82]$. In a large series of 663 patients who underwent TAVI with CoreValve, a postimplantation paravalvular leak of 2 or greater was a major risk factor for 30-day and 1-year mortality [16]. Using a larger-diameter prosthesis to overstretch the aortic annulus into a rounder shape may improve the attachment between the prosthesis and the annulus and may reduce the risk of paravalvular leak; yet this maneuver would increase the risk of embolizing the debris from the calcified valve into the coronary arteries or rupture the aortic annulus. With a severe paravalvular leak, assuming that the prosthesis has been correctly positioned, a post-dilatation may be necessary [76] and has been shown to improve paravalvular leaks. However, the post-dilatation has also been associated with a minimal but serious risk of rupture of the aortic annulus.

Recently, some authors have reported the efficacy of the aortic regurgitation (AR) index to estimate the significance of paravalvular leak and its impact on 1-year mortality after TAVI. The AR index can provide additional prognostic information to complement the echocardiographic assessment of paravalvular leak [83]. Sinning et al. [83] studied paravalvular leak in 146 TAVI patients with CoreValve. In addition to echocardiographic evaluation of paravalvular leak, the AR index was calculated as a ratio of the gradient between diastolic blood pressure (DBP) and left ventricular enddiastolic pressure (LVEDP) to systolic blood pressure (SBP): [(DBP - LVEDP $) / S B P] \times 100$. An AR index $<25$ had a significantly increased 1-year mortality risk compared with an AR index $\geq 25$ (46.0\% versus 16.7\%) [83]. Echocardiographic paravalvular leak remained a significant predictor of 1-year mortality; [83] a combination of echocardiographic paravalvular leak and AR index predicted the risk of mortality more precisely. Patients with moderate/severe paravalvular leak and an AR index $<25$ had the worst outcomes, with a 1-year mortality rate of $70 \%$ [83]. It should be noted that AR index depends on LVEDP and other hemodynamic parameters, which might be affected by preexisting cardiac conditions.

In addition to calcifications of the annulus and the native valve, prosthesis malposition, and/or annulus-prosthesis-size mismatch are some of the risk factors for paravalvular leak $[79,82,84]$.

Some authors have recommended a certain degree of prosthesis oversizing $[79,82,84]$ for an adequate adaptation of the prosthesis to the aortic annulus. Conversely, recent data have shown that oversizing of the valve was not able to reduce the incidence or the severity of paravalvular leak [81], which indicates that the paravalvular leak is a multifactorial issue and mandates that surgeons consider each case individually in terms of size, type of valve, and access. Correction of a deep implantation depth of the prosthesis can be overcome by using snare catheters or repositioning the prosthesis; by contrast, the implantation of a second prosthesis ("valvein-valve") should only be considered as a last resort for misplaced or embolized valves [79].

4.5. AV Block. An atrioventricular (AV) block requiring a permanent pacemaker (PPM) implantation occurs in $10-50 \%$ of patients following TAVI $[85,86]$. Post-TAVI electrocardiogram monitoring should be continued for a few days, especially in patients with higher risk of AV block [48]. This conduction disturbance is caused by damage to the bundle of His or the AV node [87]. Figure 5 shows the anatomic relationship of the aortic annulus and its proximity to the conduction system. Implantation of a larger prosthesis into a smaller annulus carries a higher risk for AV block [48]. In a series of 151 patients who underwent TAVI using a Sapien valve (either transapical or transfemoral), the incidence of complete AV block was 5.3\% [50]. The AV-block incidence and need for PPM implantation are higher with CoreValve implantation [88-90]. This observation was confirmed by Erkapic et al. [91] in a meta-analysis including 5,258 patients from 32 studies (Sapien valve $n=2,887$ and CoreValve $n=$ 2,371). The incidence of PPM implantation after TAVI was 15.0\%, 25.8\% after CoreValve, and 6.5\% after Sapien valve implantation [91]. A preexisting right bundle branch block (RBBB) is associated with higher risk of postprocedural AV block and subsequent pacemaker implantation [32, 89, 90, $92,93]$. In addition to RBBB and type of valve, a deep valve implantation $(<6 \mathrm{~mm}$ from the lower edge of the noncoronary cusp to the ventricular end of the prosthesis) is another risk factors for periprocedural AV block [90]. The risk of postoperative AV block increases by 2-fold following a large valve implantation in a small annulus, 4fold with using CoreValve versus the Sapien valve, and 5fold in presence of AV block episode during the procedure [48]. Some other risk factors for significant AV block and PPM implantation following TAVI include patients' age $>75$ years, oversizing $>4 \mathrm{~mm}$, and bradycardia $(<55$ beats per minute) preoperatively and on the first postoperative day [85]. Calcification load of the native valve and device landing zone are other risk factors for post-TAVI AV block requiring PPM implantation [76]. The majority of AV blocks occur within 3-7 days, which underscores the importance of close electrocardiographic followup during this period $[48,91]$. Almost half of AV blocks during TAVI occur with balloon dilatation; about half of these improve on first postoperative day [94]. 


\section{Summary}

Current evidence has demonstrated that TAVI is a feasible alternative to surgical aortic valve replacement in certain patients. Knowing the potential complications may help surgeons make the right decision for each patient depending on the patient's preexisting morbidities. Future clinical studies need to focus on individualizing each specific valve and access route to each patient's anatomy and general condition. Further, guided by clinical studies, the indication for TAVI may be expanded to intermediate- and lower-risk patients with aortic stenosis.

\section{References}

[1] A. N. Azadani, N. Jaussaud, P. B. Matthews et al., "Valve-in-valve implantation using a novel supravalvular transcatheter aortic valve: proof of concept," Annals of Thoracic Surgery, vol. 88, no. 6, pp. 1864-1869, 2009.

[2] A. Cheung and R. Ree, "Transcatheter Aortic Valve Replacement," Anesthesiology Clinics, vol. 26, no. 3, pp. 465-479, 2008.

[3] B. G. Hynes and J. Rodes-Cabau, "Transcatheter aortic valve implantation and cerebrovascular events: the current state of the art," Annals of the New York Academy of Sciences, vol. 1254, pp. 151-163, 2012.

[4] S. Neragi-Miandoab, E. Skripochnik, and R. E. Michler, "Recently patented and widely used valves for transcatheter aortic valve implantation," Recent Patents on Cardiovascular Drug Discovery, vol. 7, no. 3, pp. 196-205, 2012.

[5] C. R. Smith, M. B. Leon, M. J. Mack et al., "Transcatheter versus surgical aortic-valve replacement in high-risk patients," New England Journal of Medicine, vol. 364, no. 23, pp. 2187-2198, 2011.

[6] M. Gilard, H. Eltchaninoff, B. Iung et al., "Registry of transcatheter aortic-valve implantation in high-risk patients," New England Journal of Medicine, vol. 366, no. 18, pp. 1705-1715, 2012.

[7] J. Rodés-Cabau, J. G. Webb, A. Cheung et al., "Transcatheter aortic valve implantation for the treatment of severe symptomatic aortic stenosis in patients at very high or prohibitive surgical risk: acute and late outcomes of the multicenter Canadian experience," Journal of the American College of Cardiology, vol. 55, no. 11, pp. 1080-1090, 2010.

[8] D. Himbert, F. Pontnau, D. Messika-Zeitoun et al., "Feasibility and outcomes of transcatheter aortic valve implantation in high-risk patients with stenotic bicuspid aortic valves," American Journal of Cardiology, vol. 110, no. 6, pp. 877-883, 2012.

[9] E. Grube, L. Buellesfeld, R. Mueller et al., "Progress and current status of percutaneous aortic valve replacement: results of three device generations of the CoreValve Revalving system," Circulation, vol. 1, no. 3, pp. 167-175, 2008.

[10] D. Himbert, F. Descoutures, N. Al-Attar et al., "Results of transfemoral or transapical aortic valve implantation following a uniform assessment in high-risk patients with aortic stenosis," Journal of the American College of Cardiology, vol. 54, no. 4, pp. 303-311, 2009.

[11] J. Kempfert, A. Rastan, D. Holzhey et al., "Transapical aortic valve implantation: analysis of risk factors and learning experience in 299 patients," Circulation, vol. 124, no. 11, supplement, pp. S124-S129, 2011.

[12] M. Thomas, G. Schymik, T. Walther et al., "Thirty-day results of the SAPIEN aortic bioprosthesis European outcome (SOURCE) registry: a European registry of transcatheter aortic valve implantation using the edwards SAPIEN valve," Circulation, vol. 122, no. 1, pp. 62-69, 2010.

[13] M. Thomas, G. Schymik, T. Walther et al., "One-year outcomes of cohort 1 in the edwards Sapien aortic bioprosthesis european outcome (SOURCE) registry. The European registry of transcatheter aortic valve implantation using the edwards Sapien valve," Circulation, vol. 124, no. 4, pp. 425-433, 2011.

[14] S. K. Kodali, M. R. Williams, C. R. Smith et al., "Two-year outcomes after transcatheter or surgical aortic-valve replacement," New England Journal of Medicine, vol. 366, no. 18, pp. 1686-1695, 2012.

[15] P. Y. Litzler, B. Borz, H. Smail et al., "Transapical aortic valve implantation in Rouen: four years' experience with the Edwards transcatheter prosthesis," Archives of Cardiovascular Diseases, vol. 105, no. 3, pp. 141-145, 2012.

[16] C. Tamburino, D. Capodanno, A. Ramondo et al., "Incidence and predictors of early and late mortality after transcatheter aortic valve implantation in 663 patients with severe aortic stenosis," Circulation, vol. 123, no. 3, pp. 299-308, 2011.

[17] P. Avanzas, A. J. Muñoz-García, J. Segura et al., "Percutaneous implantation of the CoreValve self-expanding aortic valve prosthesis in patients with severe aortic stenosis: early experience in Spain," Revista Espanola de Cardiologia, vol. 63, no. 2, pp. 141$148,2010$.

[18] M. Gotzmann, W. Bojara, M. Lindstaedt et al., "One-year results of transcatheter aortic valve implantation in severe symptomatic aortic valve stenosis," American Journal of Cardiology, vol. 107, no. 11, pp. 1687-1692, 2011.

[19] S. Bleiziffer, D. Mazzitelli, A. Opitz et al., "Beyond the shortterm: clinical outcome and valve performance 2 years after transcatheter aortic valve implantation in 227 patients," Journal of Thoracic and Cardiovascular Surgery, vol. 143, no. 2, pp. 310317, 2012.

[20] T. Drews, "Transcatheter aortic valve implantation after previous coronary artery bypass grafting: a potential gold standard of care," European Journal Cardio-Thoracic Surgery, vol. 41, no. 3, pp. 504-505, 2012.

[21] S. Neragi-Miandoab, F. W. Mohr, M. A. Borger, and D. M. Holzhey, "Transapical implantation of an Edwards Sapien valve into a failed prosthetic mitral valve 3 years after a transapical aortic valve implantation," Journal of Thoracic and Cardiovascular Surgery, vol. 145, no. 2, pp. e19-e21, 2013.

[22] J. Nordmeyer, P. Lurz, V. T. Tsang et al., "Effective transcatheter valve implantation after pulmonary homograft failure: a new perspective on the Ross operation," Journal of Thoracic and Cardiovascular Surgery, vol. 138, no. 1, pp. 84-88, 2009.

[23] J. Rodés-Cabau, E. Dumont, and D. Doyle, “"Valve-in-valve” for the treatment of paravalvular leaks following transcatheter aortic valve implantation," Catheterization and Cardiovascular Interventions, vol. 74, no. 7, pp. 1116-1119, 2009.

[24] M. J. Mack, "Risk scores for predicting outcomes in valvular heart disease: how useful?" Current Cardiology Reports, vol. 13, no. 2, pp. 107-112, 2011.

[25] J. G. Webb, L. Altwegg, J. B. Masson, S. Al Bugami, A. Al Ali, and R. A. Boone, "A new transcatheter aortic valve and percutaneous valve delivery system," Journal of the American College of Cardiology, vol. 53, no. 20, pp. 1855-1858, 2009.

[26] J. Rodes-Cabau, "Transcatheter aortic valve implantation: current and future approaches," Nature Reviews Cardiology, vol. 9, no. 1, pp. 15-29, 2012. 
[27] O. Wendler, M. Thielmann, H. Schroefel et al., "Worldwide experience with the 29-mm Edwards SAPIEN XTTM transcatheter heart valve in patients with large aortic annulus," European Journal Cardio-Thoracic Surgery, vol. 43, no. 2, pp. 371-377, 2013.

[28] E. Ferrari, C. Marcucci, C. Sulzer, and L. K. von Segesser, "Which available transapical transcatheter valve fits into degenerated aortic bioprostheses?" Interactive Cardiovascular and Thoracic Surgery, vol. 11, no. 1, pp. 83-85, 2010.

[29] L. Ardies, T. Vancauwenberghe, T. De Beule, M. de Booij, and P. K. Vanhoenacker, "MDCT imaging before transcutanous aortic valve implantation: rationale and measurements," JBR-BTR, vol. 94, no. 6, pp. 315-318, 2011.

[30] J. L. Zamorano, L. P. Badano, C. Bruce et al., "EAE/ASE recommendations for the use of echocardiography in new transcatheter interventions for valvular heart disease," European Heart Journal, vol. 32, no. 17, pp. 2189-2214, 2011.

[31] J. Webb and A. Cribier, "Percutaneous transarterial aortic valve implantation: what do we know?" European Heart Journal, vol. 32, no. 2, pp. 140-147, 2011.

[32] M. Liang, G. Devlin, and S. Pasupati, "The incidence of transcatheter aortic valve implantation-related heart block in self-expandable Medtronic CoreValve and balloon-expandable Edwards valves," Journal of Invasive Cardiology, vol. 24, no. 4, pp. 173-176, 2012.

[33] G. P. Ussia, M. Barbanti, A. S. Petronio et al., “Transcatheter aortic valve implantation: 3-year outcomes of self-expanding CoreValve prosthesis," European Heart Journal, vol. 33, no. 8, pp. 969-976, 2012.

[34] C. Tamburino, M. Barbanti, D. Capodanno et al., "Comparison of complications and outcomes to one year of transcatheter aortic valve implantation versus surgical aortic valve replacement in patients with severe aortic stenosis," American Journal of Cardiology, vol. 109, no. 10, pp. 1487-1493, 2012.

[35] J. G. Webb, L. Altwegg, R. H. Boone et al., "Transcatheter aortic valve implantation: impact on clinical and valve-related outcomes," Circulation, vol. 119, no. 23, pp. 3009-3016, 2009.

[36] M. Bande, I. Michev, A. S. P. Sharp, A. Chieffo, and A. Colombo, "Percutaneous transcatheter aortic valve implantation: past accomplishments, present achievements and applications, future perspectives," Cardiology in Review, vol. 18, no. 3, pp. 111-124, 2010.

[37] T. A. Szabo, J. M. Toole, K. J. Payne, E. M. Giblin, S. P. Jacks, and R. D. Warters, "Management of aortic valve bypass surgery," Seminars in Cardiothoracic and Vascular Anesthesia, vol. 16, no. 1, pp. 52-58, 2012.

[38] T. Walther, T. Dewey, M. A. Borger et al., "Transapical aortic valve implantation: step by step," Annals of Thoracic Surgery, vol. 87, no. 1, pp. 276-283, 2009.

[39] M. Johansson, S. Nozohoor, P. O. Kimblad, J. Harnek, G. K. Olivecrona, and J. Sjgren, "Transapical versus transfemoral aortic valve implantation: a comparison of survival and safety," Annals of Thoracic Surgery, vol. 91, no. 1, pp. 57-63, 2011.

[40] H. Eggebrecht, A. Schmermund, T. Voigtländer, P. Kahlert, R. Erbel, and R. H. Mehta, "Risk of stroke after transcatheter aortic valve implantation (TAVI): a meta-analysis of 10,037 published patients," EuroIntervention, vol. 8, no. 1, pp. 129-138, 2012.

[41] A. S. Petronio, M. De Carlo, F. Bedogni et al., "2-year results of CoreValve implantation through the subclavian access: a propensity-matched comparison with the femoral access," Journal of the American College of Cardiology, vol. 60, no. 6, pp. 502507, 2012.
[42] R. R. Makkar, G. P. Fontana, H. Jilaihawi et al., "Transcatheter aortic-valve replacement for inoperable severe aortic stenosis," New England Journal of Medicine, vol. 366, no. 18, pp. 1696-1704, 2012.

[43] C. Tamburino, M. Barbanti, D. Capodanno et al., "Early- and mid-term outcomes of transcatheter aortic valve implantation in patients with logistic EuroSCORE less than 20\%: a comparative analysis between different risk strata," Catheterization and Cardiovascular Interventions, vol. 79, no. 1, pp. 132-140, 2012.

[44] M. B. Leon, N. Piazza, E. Nikolsky et al., "Standardized endpoint definitions for transcatheter aortic valve implantation clinical trials: a consensus report from the Valve Academic Research Consortium," European Heart Journal, vol. 32, no. 2, pp. 205217, 2011.

[45] A. Zierer, G. Wimmer-Greinecker, S. Martens, A. Moritz, and M. Doss, "Is transapical aortic valve implantation really less invasive than minimally invasive aortic valve replacement?" Journal of Thoracic and Cardiovascular Surgery, vol. 138, no. 5, pp. 1067-1072, 2009.

[46] Y. Boudjemline, G. Agnoletti, D. Bonnet et al., "Steps toward the percutaneous replacement of atrioventricular valves: an experimental study," Journal of the American College of Cardiology, vol. 46, no. 2, pp. 360-365, 2005.

[47] G. P. Ussia, M. Barbanti, K. Sarkar et al., "Transcatheter aortic bioprosthesis dislocation: technical aspects and midterm follow-up," EuroIntervention, vol. 7, no. 11, pp. 1285-1292, 2012.

[48] S. Bleiziffer, H. Ruge, J. Hörer et al., "Predictors for newonset complete heart block after transcatheter aortic valve implantation," Cardiovascular Interventions, vol. 3, no. 5, pp. 524-530, 2010.

[49] R. J. M. Nuis, N. M. Van Mieghem, A. Tzikas et al., "Frequency, determinants, and prognostic effects of acute kidney injury and red blood cell transfusion in patients undergoing transcatheter aortic valve implantation," Catheterization and Cardiovascular Interventions, vol. 77, no. 6, pp. 881-889, 2011.

[50] M. Z. Khawaja, M. Sohal, H. Valli et al., "Standalone balloon aortic valvuloplasty: indications and outcomes from the UK in the transcatheter valve era," Catheterization and Cardiovascular Interventions, vol. 81, no. 2, pp. 366-373, 2013.

[51] S. H. Ewe, N. Ajmone Marsan, M. Pepi et al., "Impact of left ventricular systolic function on clinical and echocardiographic outcomes following transcatheter aortic valve implantation for severe aortic stenosis," American Heart Journal, vol. 160, no. 6, pp. 1113-1120, 2010.

[52] K. Hayashida, T. Lefèvre, B. Chevalier et al., "True percutaneous approach for transfemoral aortic valve implantation using the Prostar XL device: impact of learning curve on vascular complications," Cardiovascular Interventions, vol. 5, no. 2, pp. 207-214, 2012.

[53] I. Ben-Dor, A. D. Pichard, L. F. Satler et al., "Complications and outcome of balloon aortic valvuloplasty in high-risk or inoperable patients," Cardiovascular Interventions, vol. 3, no. 11, pp. 1150-1156, 2010.

[54] H. Eltchaninoff, A. Prat, M. Gilard et al., "Transcatheter aortic valve implantation: early results of the FRANCE (FRench Aortic National CoreValve and Edwards) registry," European Heart Journal, vol. 32, no. 2, pp. 191-197, 2011.

[55] V. Stratiev, P. Guyon, E. Teiger, and J. P. Collet, "Reducing the risk of vascular complications during percutaneous aortic valve replacement," Annales de Cardiologie et d Angéiologie, vol. 61, no. 4, pp. 281-286, 2012. 
[56] N. M. Van Mieghem, D. Tchetche, A. Chieffo et al., "Incidence, predictors, and implications of access site complications with transfemoral transcatheter aortic valve implantation," American Journal of Cardiology, vol. 110, no. 9, pp. 1361-1367, 2012.

[57] S. Stortecky, P. Wenaweser, N. Diehm et al., "Percutaneous management of vascular complications in patients undergoing transcatheter aortic valve implantation," Cardiovascular Interventions, vol. 5, no. 5, pp. 515-524, 2012.

[58] H. Eltchaninoff, E. Durand, B. Borz et al., "Prospective analysis of 30-day safety and performance of transfemoral transcatheter aortic valve implantation with Edwards SAPIEN XT versus SAPIEN prostheses," Archives of Cardiovascular Diseases, vol. 105, no. 3, pp. 132-140, 2012.

[59] D. Tchetche, R. M. Van der Boon, N. Dumonteil et al., "Adverse impact of bleeding and transfusion on the outcome post-transcatheter aortic valve implantation: insights from the Pooled-RotterdAm-Milano-Toulouse In Collaboration Plus (PRAGMATIC Plus) initiative," American Heart Journal, vol. 164, no. 3, pp. 402-409, 2012.

[60] S. C. Knipp, P. Kahlert, D. Jokisch et al., "Cognitive function after transapical aortic valve implantation: a single-centre study with 3-month follow-up," Interactive Cardio Vasc Thoracic Surgery, vol. 16, no. 2, pp. 116-122, 2012.

[61] S. Stortecky, S. Windecker, T. Pilgrim et al., "Cerebrovascular accidents complicating transcatheter aortic valve implantation: frequency, timing and impact on outcomes," EuroIntervention, vol. 8, no. 1, pp. 62-70, 2012.

[62] C. K. Naber, A. Ghanem, A. A. Abizaid et al., "First-in-man use of a novel embolic protection device for patients undergoing transcatheter aortic valve implantation," EuroIntervention, vol. 8, no. 1, pp. 43-50, 2012.

[63] B. Reinsfelt, A. Westerlind, D. Ioanes et al., "Transcranial Doppler microembolic signals and serum marker evidence of brain injury during transcatheter aortic valve implantation," Acta Anaesthesiologica Scandinavica, vol. 56, no. 2, pp. 240-247, 2012.

[64] T. Pilgrim, "Predictors of clinical outcomes in patients with severe aortic stenosis undergoing TAVI: a multistate analysis," Circulation, vol. 5, no. 6, pp. 856-861, 2012.

[65] R. J. Nuis, N. M. Van Mieghem, C. J. Schultz et al., "Frequency and causes of stroke during or after transcatheter aortic valve implantation," American Journal of Cardiology, vol. 109, no. 11, pp. 1637-1643, 2012.

[66] L. Nombela-Franco, J. G. Webb, P. P. de Jaegere et al., “Timing, predictive factors and prognostic value of cerebrovascular events in a large cohort of patients undergoing transcatheter aortic valve implantation," Circulation, vol. 126, no. 25, pp. 30413053, 2012.

[67] A. Ghanem, A. Müller, J. M. Sinning et al., "Prognostic value of cerebral injury following transfemoral aortic valve implantation," EuroIntervention, 2012.

[68] T. A. Fairbairn, A. N. Mather, P. Bijsterveld et al., "Diffusionweighted MRI determined cerebral embolic infarction following transcatheter aortic valve implantation: assessment of predictive risk factors and the relationship to subsequent health status," Heart, vol. 98, no. 1, pp. 18-23, 2012.

[69] P. Kahlert, H. Eggebrecht, B. Plicht et al., “Towards real-time cardiovascular magnetic resonance-guided transarterial aortic valve implantation: in vitro evaluation and modification of existing devices," Journal of Cardiovascular Magnetic Resonance, vol. 12, p. 58, 2010.
[70] K. Onsea, P. Agostoni, M. Samim et al., "First-in-man experience with a new embolic deflection device in transcatheter aortic valve interventions," EuroIntervention, vol. 8, no. 1, pp. 5156, 2012.

[71] M. Z. Khawaja, M. Thomas, A. Joshi et al., "The effects of VARC-defined acute kidney injury after transcatheter aortic valve implantation (TAVI) using the Edwards bioprosthesis," EuroIntervention, 2012.

[72] F. Saia, C. Ciuca, N. Taglieri et al., "Acute kidney injury following transcatheter aortic valve implantation: incidence, predictors and clinical outcome," International Journal of Cardiology, 2012.

[73] R. J. Nuis, J. Rodés-Cabau, J. M. Sinning et al., "Blood transfusion and the risk of acute kidney injury after transcatheter aortic valve implantation," Circulation, vol. 5, no. 5, pp. 680-688, 2012.

[74] W. Y. Kong, G. Yong, and A. Irish, "Incidence, risk factors and prognosis of acute kidney injury after transcatheter aortic valve implantation," Nephrology, vol. 17, no. 5, pp. 445-451, 2012.

[75] M. Wessely, S. Rau, P. Lange et al., "Chronic kidney disease is not associated with a higher risk for mortality or acute kidney injury in transcatheter aortic valve implantation," Nephrology Dialysis Transplantation, vol. 27, no. 9, pp. 3502-3508, 2012.

[76] D. John, L. Buellesfeld, S. Yuecel et al., "Correlation of Device landing zone calcification and acute procedural success in patients undergoing transcatheter aortic valve implantations with the self-expanding CoreValve prosthesis," Cardiovascular Interventions, vol. 3, no. 2, pp. 233-243, 2010.

[77] G. Tarantini, V. Gasparetto, M. Napodano, C. Fraccaro, G. Gerosa, and G. Isabella, "Valvular leak after transcatheter aortic valve implantation: a clinician update on epidemiology, pathophysiology and clinical implications," American Journal of Cardiovascular Disease, vol. 1, no. 3, pp. 312-320, 2011.

[78] I. Ben-Dor, R. Waksman, L. F. Satler, and A. D. Pichard, "Patient selection-risk assessment and anatomical selection criteria for patients undergoing transfemoral aortic valve implantation," Cardiovascular Revascularization Medicine, vol. 11, no. 2, pp. 124-136, 2010.

[79] K. Takagi, A. Latib, R. Al-Lamee et al., "Predictors of moderateto-severe paravalvular aortic regurgitation immediately after CoreValve implantation and the impact of postdilatation," Catheterization and Cardiovascular Interventions, vol. 78, no. 3, pp. 432-443, 2011.

[80] D. Détaint, L. Lepage, D. Himbert et al., "Determinants of significant paravalvular regurgitation after transcatheter aortic valve: implantation impact of device and annulus discongruence," Cardiovascular Interventions, vol. 2, no. 9, pp. 821-827, 2009.

[81] M. A. Clavel, J. G. Webb, J. Rodés-Cabau et al., "Comparison between transcatheter and surgical prosthetic valve implantation in patients with severe aortic stenosis and reduced left ventricular ejection fraction," Circulation, vol. 122, no. 19, pp. 1928-1936, 2010.

[82] M. Abdel-Wahab, R. Zahn, M. Horack et al., "Aortic regurgitation after transcatheter aortic valve implantation: incidence and early outcome. Results from the German transcatheter aortic valve interventions registry," Heart, vol. 97, no. 11, pp. 899-906, 2011.

[83] J. M. Sinning, C. Hammerstingl, M. Vasa-Nicotera et al., "Aortic regurgitation index defines severity of peri-prosthetic regurgitation and predicts outcome in patients after transcatheter aortic valve implantation," Journal of the American College of Cardiology, vol. 59, no. 13, pp. 1134-1141, 2012. 
[84] M. A. Sherif, M. Abdel-Wahab, B. Stöcker et al., "Anatomic and procedural predictors of paravalvular aortic regurgitation after implantation of the Medtronic CoreValve bioprosthesis," Journal of the American College of Cardiology, vol. 56, no. 20, pp. 1623-1629, 2010.

[85] T. Schroeter, A. Linke, M. Haensig et al., "Predictors of permanent pacemaker implantation after Medtronic CoreValve bioprosthesis implantation," Europace, vol. 14, no. 12, pp. 17591763, 2012.

[86] H. Möllmann, J. Kempfert, C. W. Hamm, and T. Walther, "Transcatheter aortic valve implantation," Herz, vol. 35, no. 2, pp. 62-68, 2010.

[87] J. M. Rubin, P. Avanzas, R. del Valle et al., "Atrioventricular conduction disturbance characterization in transcatheter aortic valve implantation with the CoreValve prosthesis," Circulation, vol. 4, no. 3, pp. 280-286, 2011.

[88] R. J. Nuis, N. M. Van Mieghem, C. J. Schultz et al., “Timing and potential mechanisms of new conduction abnormalities during the implantation of the Medtronic CoreValve System in patients with aortic stenosis," European Heart Journal, vol. 32, no. 16, pp. 2067-2074, 2011.

[89] D. Erkapic, W. K. Kim, M. Weber et al., "Electrocardiographic and further predictors for permanent pacemaker requirement after transcatheter aortic valve implantation," Europace, vol. 12, no. 8, pp. 1188-1190, 2010.

[90] L. Roten, P. Wenaweser, E. Delacrtaz et al., "Incidence and predictors of atrioventricular conduction impairment after transcatheter aortic valve implantation," American Journal of Cardiology, vol. 106, no. 10, pp. 1473-1480, 2010.

[91] D. Erkapic, S. De Rosa, A. Kelava, R. Lehmann, S. Fichtlscherer, S. H. Hohnloser et al., "Risk for permanent pacemaker after transcatheter aortic valve implantation: a comprehensive analysis of the literature," Journal of Cardiovascular Electrophysiology, vol. 23, no. 4, pp. 391-397, 2012.

[92] N. D. Ferreira, D. Caeiro, L. Adão et al., "Incidence and predictors of permanent pacemaker requirement after transcatheter aortic valve implantation with a self-expanding bioprosthesis," Pacing and Clinical Electrophysiology, vol. 33, no. 11, pp. 13641372, 2010.

[93] R. Koos, A. H. Mahnken, O. Aktug et al., "Electrocardiographic and imaging predictors for permanent pacemaker requirement after transcatheter aortic valve implantation," The Journal of Heart Valve Disease, vol. 20, no. 1, pp. 83-90, 2011.

[94] L. Roten, S. Stortecky, F. Scarcia et al., "Atrioventricular conduction after transcatheter aortic valve implantation and surgical aortic valve replacement," Journal of Cardiovascular Electrophysiology, vol. 23, no. 10, pp. 1115-1122, 2012. 


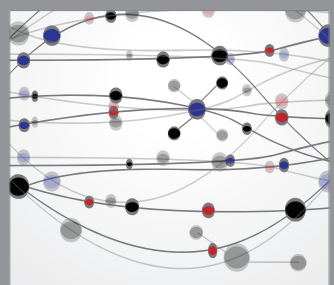

The Scientific World Journal
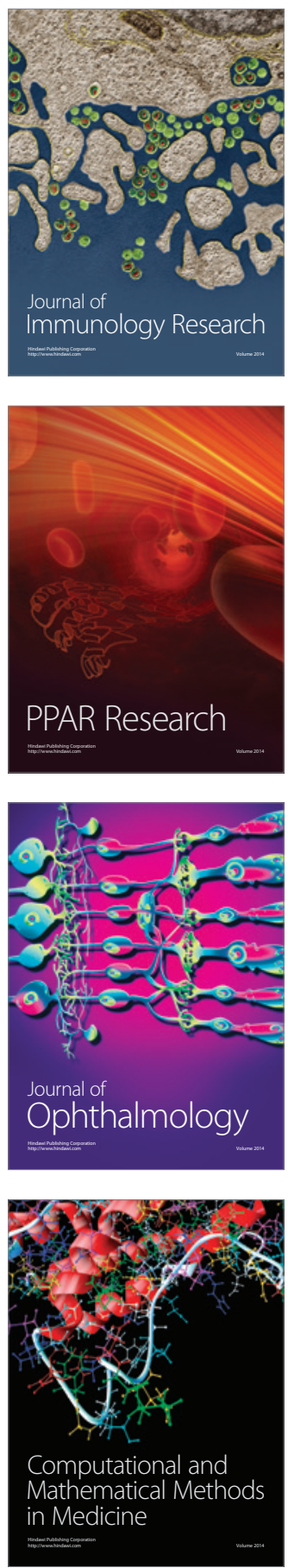

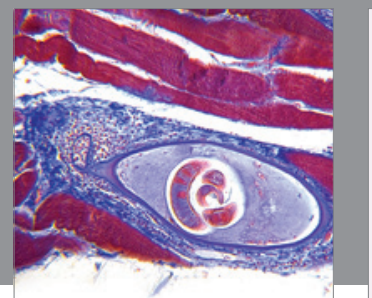

Gastroenterology

Research and Practice
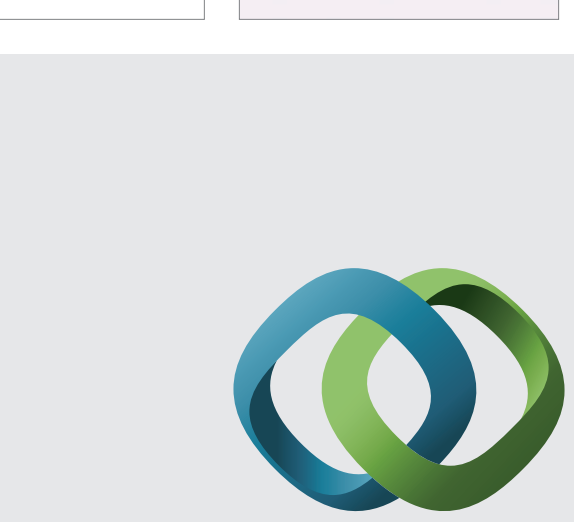

\section{Hindawi}

Submit your manuscripts at

http://www.hindawi.com
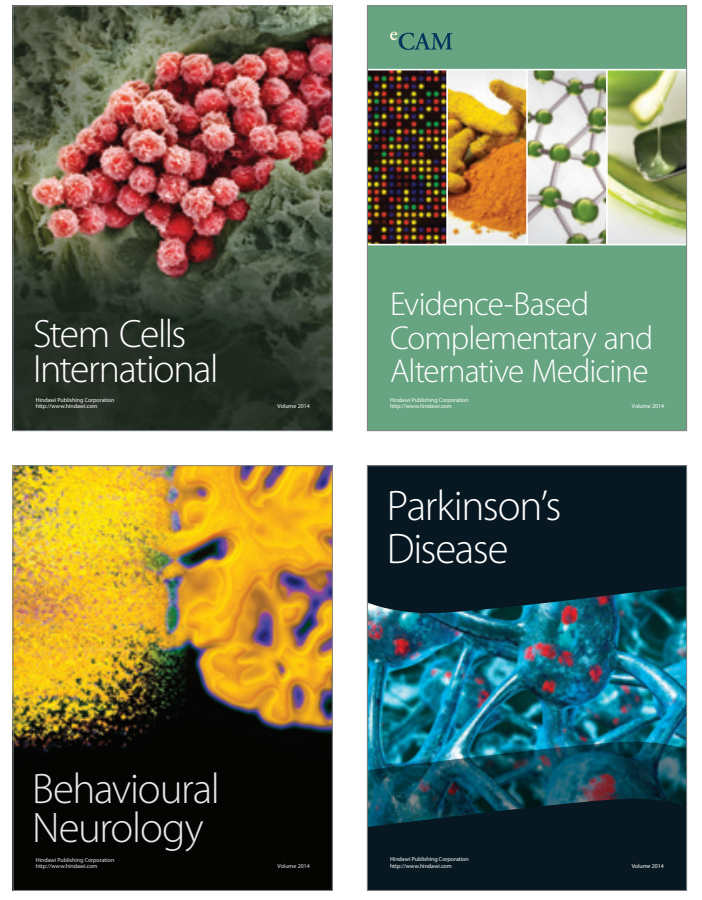
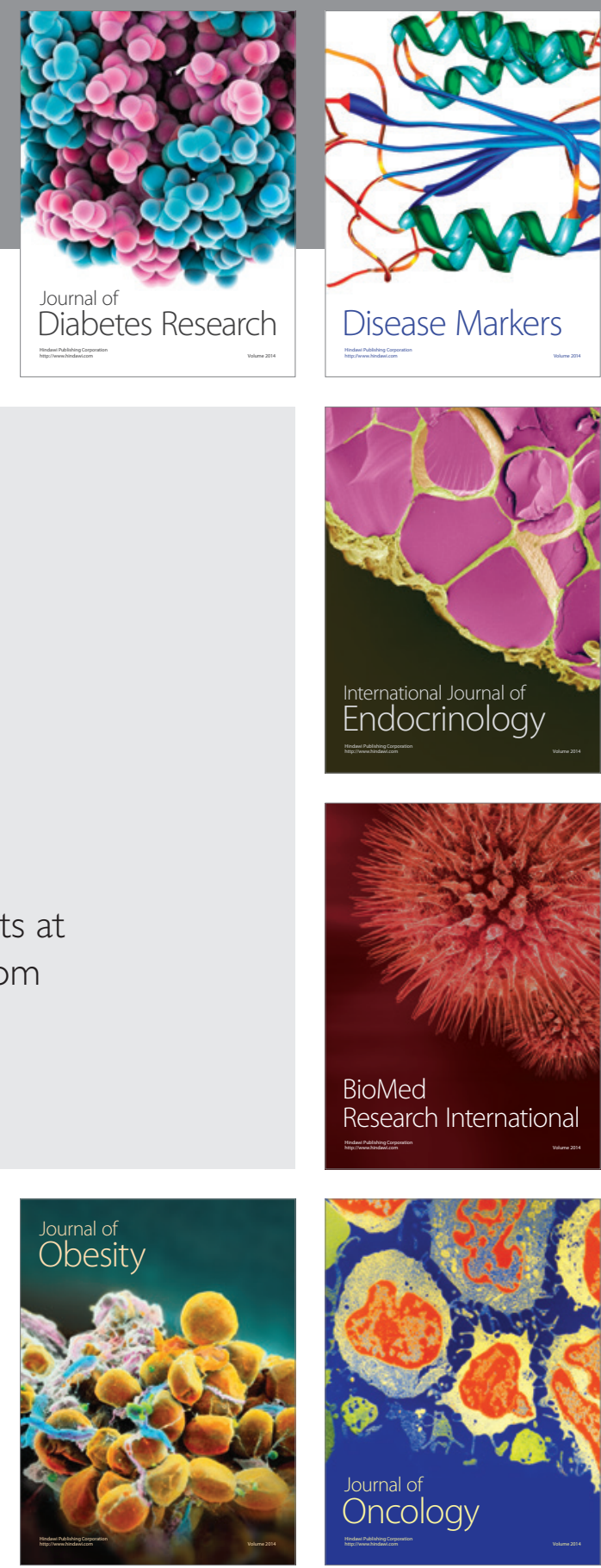

Disease Markers
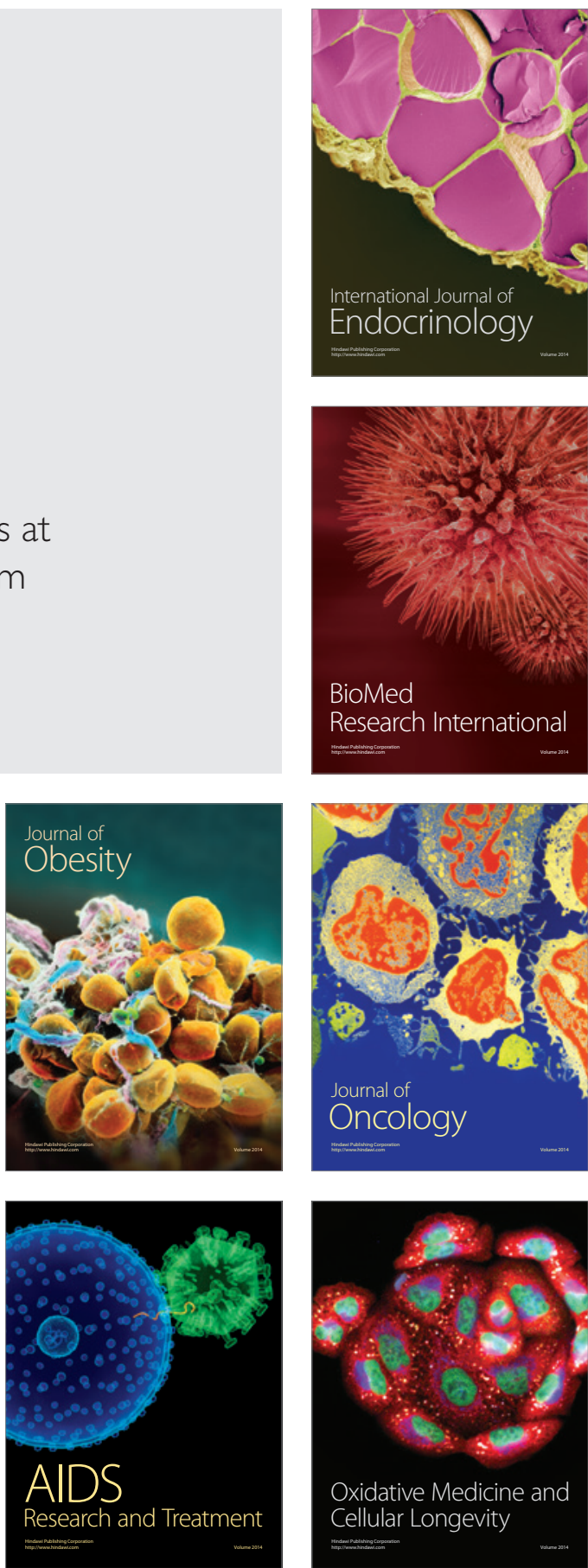